\title{
BMJ Open What are the barriers to the completion of a home-based rehabilitation programme for patients awaiting surgery for lung cancer: a prospective observational study
}

\author{
Heloise Catho, ${ }^{1}$ Sebastien Guigard, ${ }^{2}$ Anne-Claire Toffart, ${ }^{3}$ Gil Frey, ${ }^{4}$ \\ Thibaut Chollier, ${ }^{4}$ Pierre-Yves Brichon, ${ }^{4}$ Jean-François Roux,${ }^{5}$ Linda Sakhri, ${ }^{6}$ \\ Dominique Bertrand, ${ }^{7}$ Charles Aguirre, ${ }^{8}$ Sandy Gorain, ${ }^{9}$ Bernard Wuyam, ${ }^{10,11}$ \\ François Arbib, ${ }^{1}$ Jean Christian Borel (1) ${ }^{9,10}$
}

To cite: Catho $\mathrm{H}$, Guigard $\mathrm{S}$, Toffart A-C, et al. What are the barriers to the completion of a home-based rehabilitation programme for patients awaiting surgery for lung cancer: a prospective observational study. BMJ Open 2021:11:e041907. doi:10.1136/ bmjopen-2020-041907

- Prepublication history for this paper is available online. To view these files, please visit the journal online (http://dx.doi org/10.1136/bmjopen-2020041907).

Received 20 June 2020 Revised 17 November 2020 Accepted 25 January 2021

Check for updates

(C) Author(s) (or their employer(s)) 2021. Re-use permitted under CC BY-NC. No commercial re-use. See rights and permissions. Published by BMJ.

For numbered affiliations see end of article.

Correspondence to Dr Jean Christian Borel; j.borel@agiradom.com

\section{ABSTRACT}

Objectives Home-based rehabilitation programmes $(\mathrm{H}-$ $\mathrm{RPs}$ ) could facilitate the implementation of pulmonary rehabilitation prior to resection for non-small cell lung cancer (NSCLC), but their feasibility has not been evaluated. The aim of this study was to identify determinants of non-completion of an $\mathrm{H}-\mathrm{RP}$ and the factors associated with medical events occurring 30 days after hospital discharge.

Design A prospective observational study.

Intervention All patients with confirmed or suspected NSCLC were enrolled in a four-component H-RP prior to surgery: (i) smoking cessation, (ii) nutritional support, (iii) physiotherapy (at least one session/week) and (iv) home cycle-ergometry (at least three times/week).

Outcomes The H-RP was defined as 'completed' if the four components were performed before surgery.

Results Out of 50 patients included, 42 underwent surgery (80\% men; median age: 69 (IQR 25\%-75\%; 60 74) years; $64 \%$ Chronic Obstructive Pulmonary Disease (COPD); 29\% type 2 diabetes). Twenty patients (48\%) completed $100 \%$ of the programme. The median (IQR) duration of the H-RP was $32(19 ; 46)$ days. Multivariate analysis showed polypharmacy $(\mathrm{n}=24) \mathrm{OR}=12.2(95 \% \mathrm{Cl}$ 2.0 to 74.2 ), living alone $(n=8)$ (single vs couple) $O R=21.5$ $(95 \% \mathrm{Cl} 1.4$ to $>100)$ and a long delay before starting the H-RP $(n=18)$ OR=6.24 (95\% Cl 1.1 to 36.6) were independently associated with a risk of non-completion. In univariate analyses, factors associated with medical events at 30 days were H-RP non-completion, diabetes, polypharmacy, social precariousness and female sex. Conclusion Facing multiple comorbidities, living alone and a long delay before starting the rehabilitation increase the risk of not completing preoperative H-RP. Trial registration number NCT03530059.

\section{INTRODUCTION}

Lung cancer is the leading cause of cancer related deaths worldwide. ${ }^{1}$ Surgical resection for early stage non-small cell lung cancer
Strengths and limitations of this study

This is the first study to explore barriers to the completion of a home-based rehabilitation programme for patients awaiting lung resection surgery for lung cancer.

- This study provides important information to identify patients who are at risk of failure of a home-based programme.

- The sample size was small, thus the power of this exploratory study may be limited.

- The lack of collection of information relating to participation refusals means the risk of selection bias cannot be determined.

- Since no recommendations exist, the criterion on which completion of a rehabilitation programme was defined was arbitrary.

(NSCLC) offers the best chance of cure, but is associated with a risk of postoperative complications and rehospitalisation. ${ }^{2-4}$ Fragile patients are particularly at risk of such complications. ${ }^{56}$ The overall rate of hospital readmissions within 3 months after lobectomy for lung cancer can reach $18 \%$; in patients with comorbidities, each additional comorbidity was associated with a $2.0 \%$ increased probability of readmission. ${ }^{7}$ Thomas et a $\tilde{l}^{\tilde{p}}$ have shown that underweight patients had a higher surgical complication rate than normalweight patients $(23.2 \%$ vs $13.8 \%$; $<<0.001$, respectively). Guidelines from the European Respiratory Society and the European Society of Thoracic Surgery recommend early preoperative rehabilitation for patients with resectable lung cancer who have borderline lung function or poor exercise capacity. ${ }^{8}$ It is well recognised that pulmonary rehabilitation 
programmes effectively improve exercise capacity and help to maintain pulmonary function and quality of life following surgery; they also reduce the risk of developing postoperative pulmonary complications and shorten hospital stay. ${ }^{910}$ Despite those recommendations, preoperative rehabilitation programmes remain difficult to set up. The two main barriers are (i) the time available before surgery is often only a few weeks, ${ }^{11} 12$ and (ii) the lack of standardised protocols. ${ }^{9}$

Pulmonary rehabilitation is a comprehensive intervention that includes, but is not limited to, smoking cessation, nutritional support, cardiopulmonary training and physiotherapy. ${ }^{13}$ This is standard care for patients with respiratory disability and rehabilitation programmes can be conducted in both healthcare establishments and at home. ${ }^{14-16}$ However, very few studies have assessed the feasibility and efficacy of presurgery, home-based rehabilitation programmes (H-RPs). ${ }^{17}$

The aim of this study was to identify the barriers to the completion of a home-based presurgical, multimodal rehabilitation programme.

\section{METHODS}

\section{Study design}

This prospective, observational study was conducted in four different medical facilities (one tertiary university hospital and three private hospitals).

\section{Participants}

Patients were included if they (i) were at least 18 years old, (ii) had proven or suspected operable NSCLC and scheduled lung surgery, (iii) were referred for an H-RP and (iv) required at least two out of the four components of the programme (see details later). All patients were asked to participate by their lung cancer specialist during the appointment when surgery was scheduled. Written informed consent was obtained from all participants.

\section{Patients involvement}

Patients were not involved in the design, conduct, reporting or dissemination plans of our research.

\section{Components of the rehabilitation programme}

The H-RP was prescribed by a thoracic surgeon or a pulmonologist at the time the surgery date was scheduled. The minimum time before surgery should be 4 weeks.

The multimodal rehabilitation programme targeted four aspects of care that are important for good postsurgical outcomes in patients with NSCLC: (i) support for smoking cessation for active smokers, (ii) nutritional support, (iii) physiotherapy and (iv) a home-based training programme.

1. A tobacco consultation with a physician was proposed to active smokers, along with a prescription for nicotine patches.

2. Nutritional support: a dietician carried out a nutritional assessment at home; in case of nutritional de- ficiency, defined as body mass index $(\mathrm{BMI})<21$, or unintentional body weight loss $>10 \%$ in 6 months or $>5 \%$ in 1 month, food fortification advice was provided and oral nutritional supplements were prescribed. The participant's nutritional requirements were assessed by calculating the number of calories received from the 24 hours dietary recalls and compared with the required amount calculated through the HarrisBenedict equations. ${ }^{18} 19$

3. Physiotherapy consisted of weekly sessions supervised by a physiotherapist located near the participant's home (outpatient clinic). These consisted of strengthening exercises, stretching, respiratory muscle training (POWERbreathe International, Southam, UK), advice and teaching regarding the importance of breathing and coughing techniques during the postoperative period. Participants were asked to attend at least one physiotherapy session per week.

4. The training programme consisted of exercise on a cycle-ergometer. Each patient was provided with a cycleergometer at inclusion until their date of surgery. The cycle-ergometer was delivered to the patient's home by a homecare provider technician during a scheduled appointment. All patients had sufficient space within their homes for the device. Participants were asked to perform at least three 20-40 min exercise sessions per week. The initial cycling intensity was fixed at $50 \%$ of peak work rate. The participants were instructed to reach at least $30 \mathrm{~min}$ at this intensity without excessive dyspnoea $(<6 \text { on a modified Borg Scale })^{20}$ and then to progressively increase the intensity by $10 \% \mathrm{Wmax}$ increments while still being able to achieve $30 \mathrm{~min}$ of exercise. All patients were asked to complete a logbook to record the exercise sessions carried out.

\section{Data collection}

1. Demographic data (age, sex, BMI, medical history and living situation) were collected by the physician in charge in each centre.

2. Preoperative respiratory function tests were performed according to the American Thoracic Society (ATS)/ European Respiratory Society (ERS) standards. ${ }^{21}$ A symptom-limited Cardio-Pulmonary Exercise Test was performed on an electronically braked cycle ergometer with breath-by-breath expired gas analysis, determined as the highest average values over $30 \mathrm{~s}$, and peak work rate was identified. ${ }^{22}$

3. Patient-reported outcomes were assessed just before the beginning of the rehabilitation programme by using three different standard questionnaires: the Hospital Anxiety and Depression Scale (HADS), ${ }^{23}$ the Pichot fatigue scale and the French Evaluation of Deprivation and Inequalities in Health Score (EPICES) questionnaire to assess social precariousness and health inequity. ${ }^{24}$

Postoperative medical events after hospital discharge were collected by telephone interviews with participants as well as by review of their medical charts at 
the end of the study (30 days after hospital discharge). Surgical complications such as pneumothorax, pleural effusion and nerve injuries, and medical complications such as infection, prolonged pain or any other problem requiring medical attention were recorded.

\section{Outcomes}

\section{Primary outcome}

The completion rate of the rehabilitation programme was defined as the proportion of participants who completed $100 \%$ of the four components of the programme defined as follows: (i) for current smokers-initiation and maintenance of smoking cessation; (ii) for those with dietary requirements-initiation and maintenance of dietary changes; (iii) participation in at least one supervised physiotherapy session per week (this component of physiotherapy was initially determined at two supervised sessions/week but was subsequently reconsidered because it was considered too difficult to achieve); (iv) performance at least three home cycle-ergometry sessions per week.

Each component achieved was attributed a rating of $25 \%$. The smoking cessation and diet components were automatically rated as $25 \%$ if they were unnecessary (ie, former smoker at inclusion and no nutritional requirements).

Example 1: if at inclusion a participant was (i) a nonsmoker, (ii) did not need nutritional intervention, and during the H-RP participated in at least one supervised physiotherapy session/week and performed at least three home cycle-ergometry sessions/week, completion was rated as $100 \%$.

Example 2: if at inclusion a participant was (i) nonsmoker, (ii) did not need nutritional intervention, and during the H-RP participated in at least one supervised physiotherapy session/week but performed only one cycle-ergometry session/week, completion was rated as $75 \%$.

\section{Secondary outcome}

The secondary outcome was the rate of postoperative medical events assessed 30 days after hospital discharge.

We also reported early post-surgical complications before hospital discharge.

\section{Statistical analysis}

Data were analysed using SAS software V.9.4 (SAS Institute). Continuous variables were expressed as medians (25th-75th percentiles) and categorical variables were reported as absolute numbers and percentages.

To assess the determinants of completion of an H-RP, univariate logistic regression models were used (all variables were categorised (>median versus $\leq$ median). Variables that were associated with the risk of non-completion of the programme in the univariate analysis $(\mathrm{p}<0.05)$ were used to determine the optimal multivariable regression model (procedure involving all subsets with optimisation on lowest Akaike information criterion) to find the independent variables associated with the risk of non-completion of the programme. Colinearity between variables (defined as $r>0.4$ ) was verified by Pearson's or Spearman's coefficient, or Cramer's V.2. Variables associated with the risk of 30-day postdischarge events were also assessed by univariate and multivariate logistic regression models.

For all the tests, two-sided $\mathrm{p}$ values $<0.05$ were considered significant.

\section{RESULTS}

\section{Study population}

Between February 2018 and July 2019, 50 patients scheduled for surgery were included and started the programme. Eight participants were later excluded, 7 because the surgery was subsequently cancelled (small cell lung cancer $(n=2)$, metastatic disease $(n=2)$, frailty $(n=2)$, misdiagnosis $(n=1))$ and one because he withdrew his consent $(n=1))$. The characteristics of the 42 participants who completed the study are reported in table 1. Most participants were men; there was a high rate of cardio-respiratory comorbidities and exercise capacity was generally relatively low. Most participants (62\%) were non-smokers at inclusion. Twenty-four participants $(57 \%)$ required three components of the programme and $15(36 \%)$ required four components. The median delay between inclusion and the first day of rehabilitation was (median (25th-75th percentiles) 8 (6-13) days and the median delay between inclusion and surgery was 43.5 (31.0-57.0) days. The median (25th-75th) duration of the H-RP was 32 (19-46) days.

\section{Primary outcome}

The completion rate of each component of the programme and the completion rate of the overall programme is reported table 2 . Twenty participants $(48 \%)$ completed the whole programme.

Figure 1 shows the forest plots of factors related to non-completion of the rehabilitation programme: BMI at inclusion over $26.5 \mathrm{~kg} / \mathrm{m}^{2}$ (OR=6.43; 95\% CI 1.66 to 24.86, $\mathrm{p}=0.007)$, diabetes mellitus $(\mathrm{OR}=7.45 ; 95 \%$ CI 1.39 to $40.43, \mathrm{p}=0.019)$, polypharmacy ( $\geq 5$ drugs) $(\mathrm{OR}=6.31$; $95 \%$ CI 1.63 to $24.5, \mathrm{p}=0.008$ ) and a short delay between programme initiation and surgery $(\mathrm{OR}=4.67 ; 95 \% \mathrm{CI} 1.19$ to $1835, \mathrm{p}=0.028$ ) were significantly associated with the risk of non-completion in the univariate analysis. ${ }^{25}$ Living alone also tended to increase the risk of non-completion $(\mathrm{OR}=8.87 ; 95 \% \mathrm{CI} 0.98$ to $80.18, \mathrm{p}=0.052)$. The risk of non-completion was also associated with a long delay between inclusion and starting the programme $(\mathrm{OR}=4.67$; $95 \%$ CI 1.19 to $18.35, p=0.028)$. In contrast, high scores on the fatigue scale, depression and anxiety scale and social status (EPICES) were not associated with the risk of non-completion. Finally, living alone, polypharmacy and a long delay before starting the programme were the three independent variables that best explained the risk of non-completion (table 3 ). 
Table 1 Subject characteristics $(n=42)$

\begin{tabular}{|c|c|}
\hline & n (\%) or median (25th-75th) \\
\hline Age (years) & $69(60-74)$ \\
\hline Sex (\% male) & $34(81)$ \\
\hline BMI $\left(\mathrm{kg} / \mathrm{m}^{2}\right)$ & $26.5(23.4-30)$ \\
\hline Living with a partner (yes) & $34(81)$ \\
\hline Delay to start the programme (days) & $8(6-13)$ \\
\hline \multicolumn{2}{|l|}{ Medical history } \\
\hline Hypertension & $20(47.6)$ \\
\hline Cardiac arrhythmias & $3(7.1)$ \\
\hline Coronary artery disease & $4(9.5)$ \\
\hline Chronic obstructive pulmonary disease & $27(64.2)$ \\
\hline Type 2 diabetes & $12(28.6)$ \\
\hline Current Smoker & $16(38.1)$ \\
\hline \multicolumn{2}{|l|}{ Pulmonary function } \\
\hline $\mathrm{FEV}_{1}(\%$ predicted value) & $72.5(57-86)$ \\
\hline $\mathrm{FEV}_{1} / \mathrm{FVC}$ & $64(58-73)$ \\
\hline Peak work rate $(\mathrm{W})$ & $90(70-110)$ \\
\hline $\mathrm{VO}_{2}$ peak $(\mathrm{mL} / \mathrm{kg} / \mathrm{min})$ & $18(15.5-20)$ \\
\hline $\mathrm{VO}_{2}$ peak (\% predicted value) & $67(58-85)$ \\
\hline \multicolumn{2}{|l|}{ Patient reported outcomes } \\
\hline HAD anxiety scale & $7(5-11)$ \\
\hline HAD depression scale & $5(2-7)$ \\
\hline EPICES>30, n (\%) & $19(45.2)$ \\
\hline Pichot fatigue scale & $7(4-15)$ \\
\hline \multicolumn{2}{|l|}{ Postoperative cancer stage } \\
\hline Stages I-II, n (\%) & $26(61.9)$ \\
\hline Stages III, n (\%) & $11(26.2)$ \\
\hline Stages IV, n (\%) & $3(7.1)$ \\
\hline Stages other, $\mathrm{n}(\%)$ & $2(4.8)$ \\
\hline
\end{tabular}

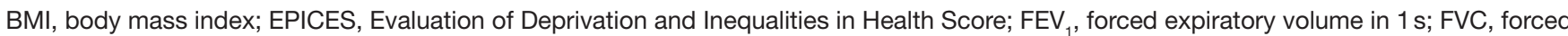
vital capacity; HAD, Hospital Anxiety and Depression; $\mathrm{VO}_{2}$, oxygen consumption.

\section{Secondary outcomes}

Thirteen patients participants $(31 \%)$ had at least one postoperative medical event within 30 days of hospital discharge (one recurrent nerve injury, one pneumothorax, two late postoperative episodes of severe pain

Table 2 Completion rate for each component of the programme

\begin{tabular}{lll}
\hline & $\begin{array}{l}\text { Number of patients } \\
\text { concerned }\end{array}$ & $\begin{array}{l}\text { Completion } \\
\text { rate, } \mathbf{n}(\%)\end{array}$ \\
\hline Smoking cessation & 16 & $12(75)$ \\
\hline Nutritional support & 38 & $30(79)$ \\
\hline Physiotherapy & 42 & $31(74)$ \\
Exercise training & 42 & $33(79)$ \\
\hline Full programme & 42 & $20(48)$ \\
\hline
\end{tabular}

and/or pain that was not alleviated by treatment, five infections, one pleural effusion, one transfusion for haemorrhage of a stomach ulcer, one hypertensive crisis and one postsurgical anaemia).

Figure 2 shows the forest-plots of factors related to the occurrence of at least one medical event after hospital discharge. Diabetes mellitus $(\mathrm{p}=0.020)$, polypharmacy ( $\geq 5$ drugs) $(\mathrm{p}=0011)$, social precariousness $(\mathrm{p}=0.043)$ and female sex $(\mathrm{p}=0.043)$ were significantly associated with the occurrence of late complications in the univariate analysis. Non-completion of the programme was also associated with the risk of late complications. It was not possible to build a multivariate model to determine independent variables due to the high colinearity between the variables.

Table 4 reports early postsurgical complications (before hospital discharge) and length of hospitalisation: 
Figure 1.

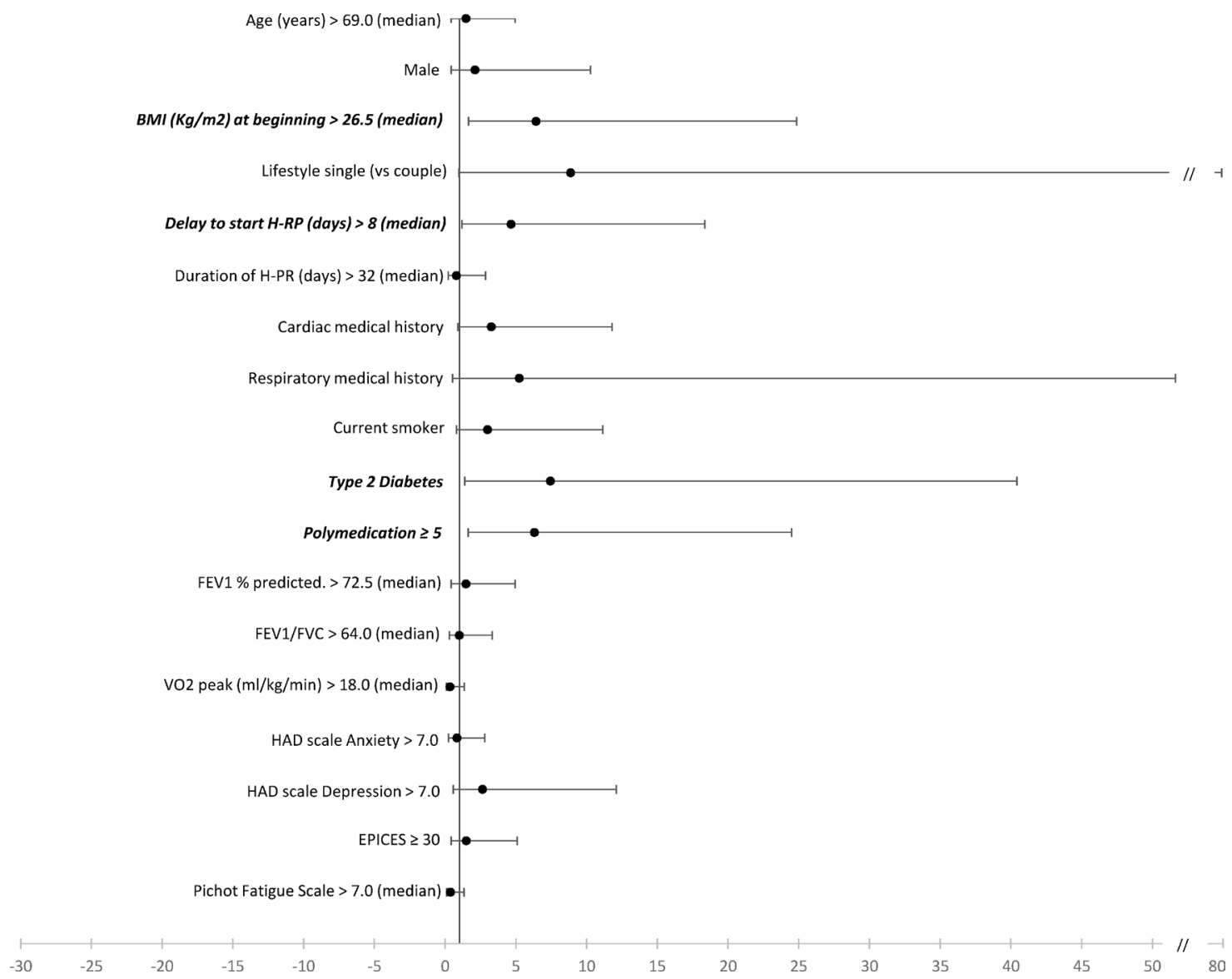

Figure 1 Forests plots: ORs related to non-completion of the rehabilitation programme (univariate analyses). BMI, body mass index; EPICES, Evaluation of Deprivation and Inequalities in Health Score; FEV ${ }_{1}$, forced expiratory volume in $1 \mathrm{~s}$; FVC, forced vital capacity; $\mathrm{H}-\mathrm{RP}$, home-based rehabilitation programme; HAD, Hospital Anxiety and Depression; $\mathrm{VO}_{2}$, oxygen consumption.

neither early postsurgical complications nor the duration of hospitalisation differed between participants who had completed the H-RP and those who had not.

\section{DISCUSSION}

The aim of this prospective study was to identify barriers to the completion of a H-RP for patients awaiting lung resection surgery for lung cancer. Living alone, polypharmacy and a long delay before starting the rehabilitation programme were the main factors associated with the risk of not completing the programme. Furthermore, the results showed that polypharmacy, social precariousness and non-completion of the rehabilitation programme were associated with a risk of late medical events.
Although the impact of the delay between the diagnosis of NSCLC and surgery on patient prognosis is still debated ${ }^{26}$ current guidelines recommend that this time should be minimised ( 6 weeks). ${ }^{27-29}$ Thus, any delay in the implementation of the rehabilitation programme reduces the possibility of completing the programme, especially if the date of surgery is already scheduled. In the present study, all patients were prescribed presurgical pulmonary rehabilitation by a lung cancer specialist as soon as surgery was scheduled. The initiation of the rehabilitation programme could be delayed either by the time required to pass a cardio-respiratory test (cardiac clearance) or because of patient related constraints (difficulty in scheduling an appointment). Our results show that a period of at least 6 weeks is likely to be required

Table 3 Factors associated with the risk of not completing the rehabilitation programme in the multivariate analysis

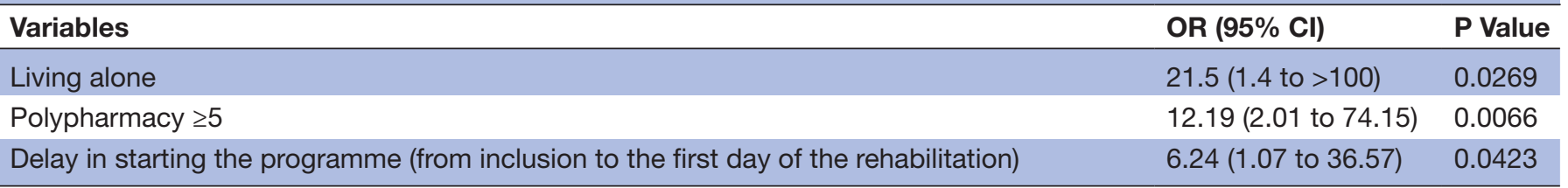

Result of Akaike information criterion=47.4 (lower values indicate a better model), $\mathrm{p}$ value global test=0.0225. 


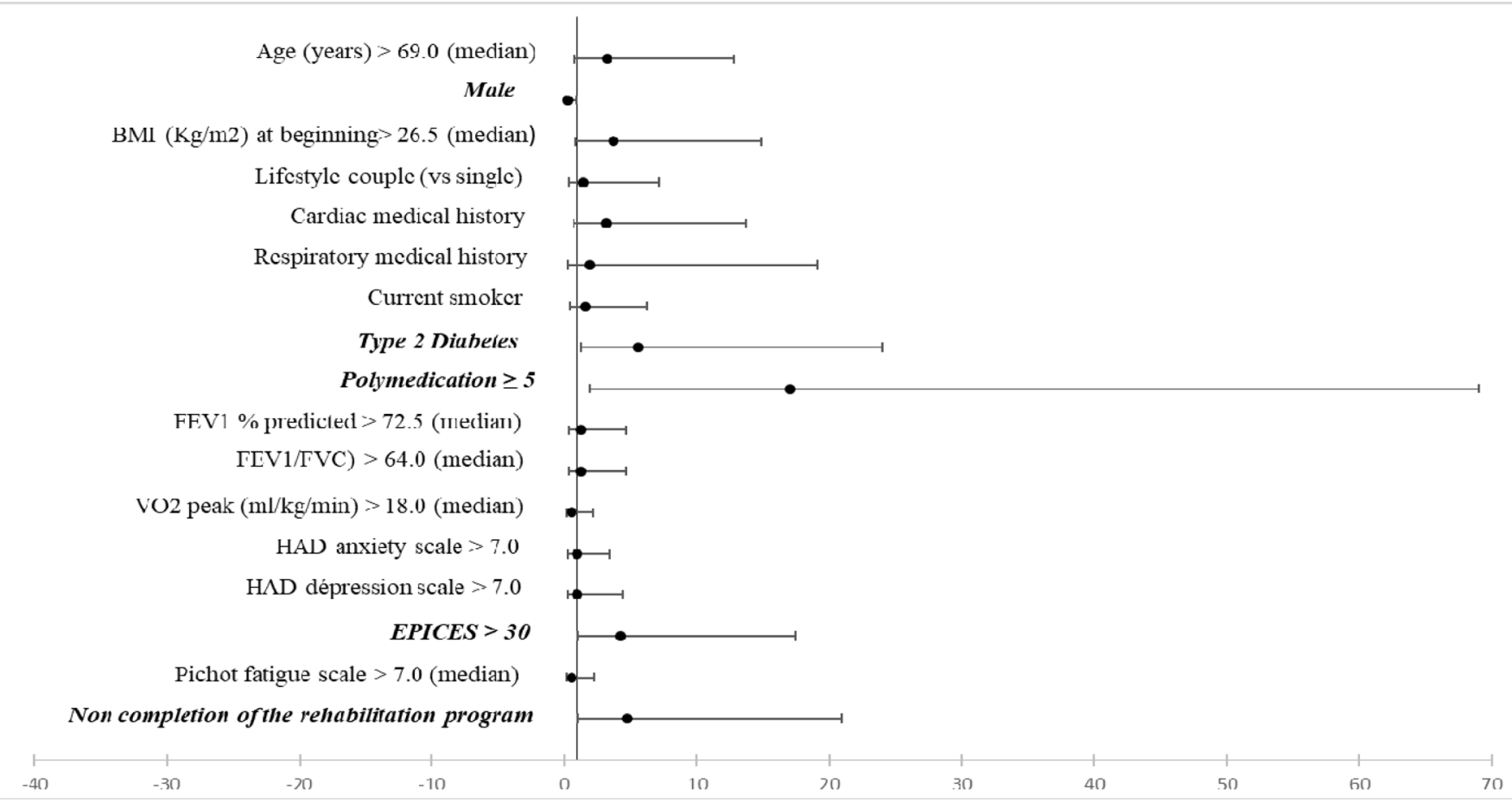

Figure 2 Forests plots: ORs related to one adverse event or more (univariate analyses). BMI, body mass index; EPICES, Evaluation of Deprivation and Inequalities in Health Score; $\mathrm{FEV}_{1}$, forced expiratory volume in $1 \mathrm{~s} ; \mathrm{FVC}$, forced vital capacity;HAD, Hospital Anxiety and Depression; $\mathrm{VO}_{2}$, oxygen consumption.

to complete such a pre-surgical pulmonary rehabilitation programme.

One of the main patient-related factors that prevented the completion of the home-based programme was polypharmacy. Polypharmacy indicates the presence of multimorbidity, which can be burdensome for individuals to manage (drug management, self-monitoring, visits to the doctor, laboratory tests, etc). In a very elegant modelling approach, Buffel du Vaure et $a l^{30}$ showed that people who have diabetes and hypertension could spent about 40 hours/month managing their pathologies. It is therefore reasonable to expect that the diagnosis of cancer, along with the examinations and appointments involved, considerably increases this burden and limits engagement in a rehabilitation programme. However, it was surprising that engagement did not seem to be limited by mood in this study, since there was no relationship between noncompletion of the programme and anxiety-depression or fatigue scores. Furthermore, the results also showed that both patients with multimorbidity and those in precarious social situations were also at risk of late postsurgical complications. In the light of these important results, we suggest that inpatient presurgical rehabilitation programmes might be more appropriate for patients with multimorbidity and those in precarious social situations than home-based programmes to enhance postsurgical recovery. This issue should be the object of future research.

Several studies have shown that family support and encouragement enhance participation and adherence to pulmonary rehabilitation ${ }^{31}$ particularly when the partner is able to participate in the patient's care. ${ }^{33} \mathrm{In}$ the present study, all but one of the participants who completed the full programme lived with a partner, which explains why the upper limit of the CI for this variable was very high (table 3; OR). In contrast with recent results

Table 4 Early postsurgical complications (before discharge) and length of hospitalisation in patients who completed the H-RP versus those who did not

\begin{tabular}{lllll}
\hline Variables & $\begin{array}{l}\text { Patients who completed } \\
\text { H-RP (n=20) }\end{array}$ & $\begin{array}{l}\text { Patients who did not } \\
\text { complete H-RP (n=22) }\end{array}$ & OR (95\% Cl) & $\begin{array}{l}\mathbf{P} \\
\text { value }\end{array}$ \\
\hline Pleuro-pulmonary complications, $\mathrm{n}(\%)$ & $12(60.0)$ & $9(40.9)$ & $0.46(0.13$ to 1.59$)$ & 0.22 \\
Chest-wall complications, $\mathrm{n}(\%)$ & $1(5.0)$ & $2(9.1)$ & $1.90(0.16$ to 22.71$)$ & 0.61 \\
Cardiovascular complications, $\mathrm{n}(\%)$ & $3(15.0)$ & $3(13.6)$ & $0.90(0.16$ to 5.04$)$ & 0.90 \\
Neurological complications, $\mathrm{n}(\%)$ & $1(5.0)$ & $1(4.6)$ & $0.91(0.05$ to 15.49$)$ & 0.94 \\
$\begin{array}{l}\text { Length of postoperative hospitalisation, } \\
\text { days (median (25th-75th)) }\end{array}$ & $7.5(6.0-9.5)$ & $7.0(6.0-12.0)$ & $0.69(0.20$ to 2.35) & 0.56 \\
\hline
\end{tabular}


published on non-adherence to home-based pulmonary rehabilitation, neither depression nor anxiety scores were found to be associated with the risk of not completing the home rehabilitation programme. ${ }^{34}$

This study has several limitations. First, from a methodological point of view, although the planned sample size was recruited, the sample was small and thus the power of this exploratory study was limited. Second, the criterion on which completion of a rehabilitation programme was defined was arbitrary and we did not collect information relating to the reasons for non-completion and at which point in the process non-completion occurred. However, no recommendations regarding this type of programme have been published and most of the studies evaluating rehabilitation programme adherence only considered the number of exercise sessions performed, but not others components of rehabilitation. ${ }^{35}$ Third, it could be argued that some of the participants could have been considered at a low risk of postoperative complications, ${ }^{8}$ however, our aim was not to estimate the effect of the programme on postoperative risks but to assess the barriers to completion of the home-based programme. Fourth, we did not collect information relating to the number and the reasons for refusal, therefore, we cannot we be sure there was no selection bias.

Finally, this study was not controlled and thus conclusions cannot be drawn as to the effectiveness of the homebased programme regardless of whether it was completed by the patient or not.

\section{CONCLUSION}

The presence of multiple comorbidities and living alone were found to be the main obstacles to the completion of a home rehabilitation programme. Although other factors relating to non-completion may not have been identified, these results provide important information for clinicians to identify patients who are at risk of failure of a homebased programme and thus would benefit more from supervised pre-surgical rehabilitation programmes.

\section{Author affiliations \\ ${ }^{1}$ Department of Pneumology, University Hospital of Grenoble, Grenoble, France \\ ${ }^{2}$ Department of Thoracic surgery, Clinique Belledonne, Grenoble, France \\ ${ }^{3}$ Department of Pneumo-oncology, University Hospital of Grenoble, Grenoble, France \\ ${ }^{4}$ Department of Thoracic surgery, University Hospital of Grenoble, Grenoble, France \\ ${ }^{5}$ Department of Thoracic surgery, Clinique des Cèdres, Grenoble, France \\ ${ }^{6}$ Department of Oncology, Institut Daniel Hollard, groupe hospitalier mutualiste, \\ Grenoble, France \\ ${ }^{7}$ Pneumology, Pulmonary and Sleep Clinic, Saint Ismier, France \\ ${ }^{8}$ Physiotherapy, center Pol'air, Grenoble, France \\ ${ }^{9}$ Research and Development, Agir à Dom, Association, Meylan, France \\ ${ }^{10} \mathrm{Clinical}$ Research, HP2, INSERM U1042, Université Grenoble Alpes, Grenoble, France \\ ${ }^{11}$ Sleep Laboratory and Exercise Physiology, Thorax and Vessels Division, Grenoble Alps University Hospital, Grenoble, France}

Acknowledgements The authors thank Dre Helena Revil, Political Science Researcher at PACTE Laboratory, Université Grenoble Alpes, CNRS; we also thank Nathalie Arnol for the statistical analysis and Johanna Robertson for English editing.
Contributors Planning of the study: JCB, SGo, FA, CA, BW. Conduct of the study: SGu, FA, A-CT, GF, TC, P-YB, JF-R, LS, DB. Reporting of the study: HC, JCB, FA, SGo. JCB had full access to all study data and takes responsibility for the integrity of the data and the accuracy of the data analysis.

Funding The authors have not declared a specific grant for this research from any funding agency in the public, commercial or not-for-profit sectors.

Competing interests JCB and SGo are salaried by AGIR à dom. Other authors have no conflict of interest regarding this study.

Patient and public involvement Patients and/or the public were not involved in the design, or conduct, or reporting, or dissemination plans of this research.

Patient consent for publication Not required.

Ethics approval The study was approved by the ethics committee (CPP Ile de France XI, 2017-A02697-46). Written informed consent was obtained from all participants.

Provenance and peer review Not commissioned; externally peer reviewed.

Data availability statement Data are available upon reasonable request. Data sharing: all of the anonymised individual participant data collected during the trial are available (no end date). Requests should be directed to j.borel@agiradom.com.

Open access This is an open access article distributed in accordance with the Creative Commons Attribution Non Commercial (CC BY-NC 4.0) license, which permits others to distribute, remix, adapt, build upon this work non-commercially, and license their derivative works on different terms, provided the original work is properly cited, appropriate credit is given, any changes made indicated, and the use is non-commercial. See: http://creativecommons.org/licenses/by-nc/4.0/.

ORCID iD

Jean Christian Borel http://orcid.org/0000-0003-4140-6210

\section{REFERENCES}

1 Bray F, Ferlay J, Soerjomataram I, et al. Global cancer statistics 2018: GLOBOCAN estimates of incidence and mortality worldwide for 36 cancers in 185 countries. CA Cancer J Clin 2018;68:394-424.

2 Bhagat R, Bronsert MR, Ward AN, et al. National analysis of unplanned readmissions after thoracoscopic versus open lung cancer resection. Ann Thorac Surg 2017;104:1782-90.

3 Morgant $\mathrm{M}-\mathrm{C}$, Pagès $\mathrm{P}-\mathrm{B}$, Orsini $\mathrm{B}$, et al. Time trends in surgery for lung cancer in France from 2005 to 2012: a nationwide study. Eur Respir J 2015;46:1131-9.

4 Howington JA, Blum MG, Chang AC, et al. Treatment of stage I and II non-small cell lung cancer: diagnosis and management of lung cancer, 3rd ed: American College of chest physicians evidencebased clinical practice guidelines. Chest 2013;143:e278S-313.

5 Thomas PA, Berbis J, Falcoz P-E, et al. National perioperative outcomes of pulmonary lobectomy for cancer: the influence of nutritional status. Eur J Cardiothorac Surg 2014;45:652-9.

6 Tsiouris A, Hammoud ZT, Velanovich V, et al. A modified frailty index to assess morbidity and mortality after lobectomy. J Surg Res 2013;183:40-6.

7 Jean RA, Chiu AS, Boffa DJ, et al. When good operations go bad: the additive effect of comorbidity and postoperative complications on readmission after pulmonary lobectomy. Surgery 2018;164:294-9.

8 Brunelli A, Charloux A, Bolliger CT, et al. ERS/ESTS clinical guidelines on fitness for radical therapy in lung cancer patients (surgery and chemo-radiotherapy). Eur Respir J 2009;34:17-41.

9 Cavalheri V, Granger C. Preoperative exercise training for patients with non-small cell lung cancer. Cochrane Database Syst Rev 2017;6:CD012020.

$10 \mathrm{Ni} \mathrm{H-J,} \mathrm{Pudasaini} \mathrm{B,} \mathrm{Yuan} \mathrm{X-T,} \mathrm{et} \mathrm{al.} \mathrm{Exercise} \mathrm{training} \mathrm{for} \mathrm{patients}$ pre- and Postsurgically treated for non-small cell lung cancer: a systematic review and meta-analysis. Integr Cancer Ther 2017;16:63-73.

11 Salomaa E-R, Sällinen S, Hiekkanen H, et al. Delays in the diagnosis and treatment of lung cancer. Chest 2005;128:2282-8.

12 Lo DS, Zeldin RA, Skrastins R, et al. Time to treat: a system redesign focusing on decreasing the time from suspicion of lung cancer to diagnosis. J Thorac Oncol 2007;2:1001-6.

13 Spruit MA, Singh SJ, Garvey C, et al. An official American thoracic Society/European respiratory Society statement: key concepts and advances in pulmonary rehabilitation. Am J Respir Crit Care Med 2013;188:e13-64.

14 Borel J-C, Wuyam B, Veale D, et al. [Home pulmonary rehabilitation: results in a cohort of 37 patients with respiratory handicap]. Rev Mal Respir 2004;21:711-7. 
15 Vieira DSR, Maltais F, Bourbeau J. Home-based pulmonary rehabilitation in chronic obstructive pulmonary disease patients. Curr Opin Pulm Med 2010;16:134-43.

16 Maltais François, Maltais F, et al. Effects of home-based pulmonary rehabilitation in patients with chronic obstructive pulmonary disease. Ann Intern Med 2008;149:869-78.

17 Coats V, Maltais F, Simard S, et al. Feasibility and effectiveness of a home-based exercise training program before lung resection surgery. Can Respir J 2013;20:e10-16.

18 Harris JA, Benedict FG. A biometric study of human basal metabolism. Proc Natl Acad Sci U S A 1918;4:370-3.

19 Willett WC, Sampson L, Stampfer MJ, et al. Reproducibility and validity of a semiquantitative food frequency questionnaire. Am J Epidemiol 1985;122:51-65.

20 Mador MJ, Rodis A, Magalang UJ. Reproducibility of Borg scale measurements of dyspnea during exercise in patients with COPD. Chest 1995;107:1590-7.

21 Wanger J, Clausen JL, Coates A, et al. Standardisation of the measurement of lung volumes. Eur Respir J 2005;26:511-22.

22 Ross RM. ATS/ACCP statement on cardiopulmonary exercise testing. Am J Respir Crit Care Med 2003;167:1451.

23 Zigmond AS, Snaith RP. The hospital anxiety and depression scale. Acta Psychiatr Scand 1983;67:361-70.

24 Labbe E, Blanquet M, Gerbaud L, et al. A new reliable index to measure individual deprivation: the EPICES score. Eur J Public Health 2015;25:604-9.

25 Jyrkkä J, Enlund H, Korhonen MJ, et al. Polypharmacy status as an indicator of mortality in an elderly population. Drugs Aging 2009;26:1039-48.

26 Olsson JK, Schultz EM, Gould MK. Timeliness of care in patients with lung cancer: a systematic review. Thorax 2009;64:749-56.
27 Malalasekera A, Nahm S, Blinman PL, et al. How long is too long? A scoping review of health system delays in lung cancer. Eur Respir Rev 2018;27:180045.

28 Del Giudice ME, Young S-M, Vella ET, et al. Guideline for referral of patients with suspected lung cancer by family physicians and other primary care providers. Can Fam Physician 2014;60:711-6, e37682.

29 BTS recommendations to respiratory physicians for organising the care of patients with lung cancer. the lung cancer Working Party of the British thoracic Society standards of care Committee. Thorax 1998;53 Suppl 1:S1-8.

30 Buffel du Vaure C, Ravaud P, Baron G, et al. Potential workload in applying clinical practice guidelines for patients with chronic conditions and multimorbidity: a systematic analysis. BMJ Open 2016;6:e010119.

31 Hayton C, Clark A, Olive S, et al. Barriers to pulmonary rehabilitation: Characteristics that predict patient attendance and adherence. Respir Med 2013;107:401-7.

32 Arnold E, Bruton A, Ellis-Hill C. Adherence to pulmonary rehabilitation: a qualitative study. Respir Med 2006;100:1716-23.

33 Chen Z, Fan VS, Belza B, et al. Association between social support and self-care behaviors in adults with chronic obstructive pulmonary disease. Ann Am Thorac Soc 2017;14:1419-27.

$34 \mathrm{Li} \mathrm{Y,} \mathrm{Qian} \mathrm{H,} \mathrm{Yu} \mathrm{K,} \mathrm{et} \mathrm{al.} \mathrm{Nonadherence} \mathrm{in} \mathrm{home-based} \mathrm{pulmonary}$ rehabilitation program for COPD patients. Can Respir $J$ 2020;2020:1-7.

35 Driessen EJ, Peeters ME, Bongers BC, et al. Effects of prehabilitation and rehabilitation including a home-based component on physical fitness, adherence, treatment tolerance, and recovery in patients with non-small cell lung cancer: a systematic review. Crit Rev Oncol Hematol 2017;114:63-76. 